\title{
Linguistic developments from the perspective of the modern linguistic lesson
}

\author{
Dr. Ali Awad Maizar, Al-Muthanna University / College of Basic Education \\ Dr. Abbas Abdul Azeez Saihoob, Center for Basra and the Arabian Gulf Studies
}

\begin{abstract}
. based on tracing the most important linguistic developments witnessed by the modern linguistic lesson around the world, which included the field of syntax and semantics, and transcended them to deliberativeness, highlighting the most important linguistic systems, and the efforts initiated by linguistics scholars represented in the transformation from structural linguistics to functional linguistics, and the latest The findings of contemporary linguistic studies.

First: structural linguistics:

Structuralism is a philosophical approach that is based mainly on the abstract form and the apparent image, and includes theories that deal with the formal aspect or the apparent form of the linguistic structure regardless of the function for which the language was found in itself or the function that these structures were formed to perform. "It includes the linguistic theories that consider that natural languages are patterns An abstract whose structures can be studied in isolation from its function of communicating within societies'

(1)

Based on this principle, some structural studies concerned the characteristics of the formal text on the basis that it is a system of abstract units and structures without paying attention to its semantic and pragmatic properties that interact significantly with the formal properties, and from these structural studies: European structural theory and American structural theory, we try here To dwell on some of what we are interested in from what the two theories dealt with after we have identified the most important pioneers.
\end{abstract}

Keywords: developments, perspective, modern.

$\begin{array}{lll}\text { Received: } 03.12 .2020 & \text { Accepted: } 11.01 .2021 & \text { Published: 01.02.2021 }\end{array}$

1) European structural theory:

European structuralism appeared with the linguist (Ferdinand de Saussure), who was considered the first constructor to be an independent school, as he set up stand-alone foundations in which he defined the subject of linguistics, its terminology, and its methodology, rejecting the principles of historical study and the comparative method, as he believes that language is the only subject For linguistics, it is in itself and for itself, and it has a form organized according to the jurisprudence of sounds and perceptions, and the linguistic structure is studied in an instantaneous situation at the moment of use, based on (formalism), which means combining sounds and meanings and forming them together (2), and this combination is the essence of language, and this has become commonplace. The trend became its followers and supporters, and it was later called (the formal approach) and became the basis and subject of influence of all modern schools and most structural studies in Europe in particular and many countries of the world, especially in the first half of the twentieth century after the emergence of the book (Lessons in General Linguistics) by Ferdinan De Saussure (3), and after this trend spread and established its rules, its flaws later appeared and became the subject of criticism by many scholars, who considered it a threat to the language, and the result of these criticisms was the emergence of independent schools and currents (4).

2) American structural theory:

The American structural theory is represented by the transformative generative theory led by the American linguist (Chomsky), whose reputation is among the American theories, and it is one of the theories that believes that language can be studied as an abstract structure without looking at its function and in isolation from it (5) since it does not take into account reality This is what made it considered a non-functional structural theory despite its opposition to many of the Saussurean structural ideas, as it is faulty for its stance when describing the image (form) and not going beyond interpretation. In Chomsky's theory, in which 
structuralism was opposed to the conversion from the deep structure to the surface structure, which caused a linguistic revolution, but at the same time this theory was a starting point for criticism. Because it focused on the discourse more than it focused on the two ends of the discourse (the speaker and the speaker), the psychological and social reality of it, the circumstances of the speech and what he called for, and thus we find that the American structural theory as much as many researchers considered it is not related to de Saussure's ideas (7) others see it as It is related to one cause or another, because (de Saussure) is the true founder of modern structuralism (8) and to him "refers to what has been called structural linguistics in general" (9), but (Chomsky) in the late seventies acknowledged that the speaker has two abilities, namely: Grammatical ability, and deliberative ability (10), where the deliberative level was listed alongside the levels (phonological, morphological and compositional). This recognition may be one of the repercussions of the emergence of the functional trend that its existence appeared from the Prague School 1926 AD until it developed and acquired its deliberative character with (Simon Dick) 1978 A.D.

Second: functional linguistics:

What is meant by functional linguistics for those with a deliberative career orientation is the link between the structure of language and the function of communication, reporting and statement a link that makes the structure a reflection of the job and its dependency, as there is no consideration of linguistic units except through the functional role that is based on communication (11), so the functional direction sees that language is a social phenomenon The linguistic structure is linked to the communication function (12) and it is the sounds and meaning that form the communicative stimulus that connects the members of the linguistic community (13). The concept of language for many students has been associated with the function for which it was set up, which is communication and communication, as the language has no meaning unless its owners are able to communicate Through it and express their purposes, and the communicative function is manifested at a group of linguistic levels; Because each element in the linguistic system performs a specific function in a specific communicative context and works to prove its presence within this system, and this is what called a group of linguists to focus their efforts in highlighting the different functions of the linguistic elements, and we will address the most important of these efforts as follows:

The most important job theories and the way to differentiate between them:

There is no doubt that the linguistic lesson is constantly evolving and that it did not remain confined to structural linguistics, but rather it overlooked it with some benefit from it, thus establishing special linguistic schools concerned with job research. These schools consisted of a group of researchers, so each of them looked at the position in language with a special view. And he searched for it in a special level of the linguistic system, except that through the development of linguistic studies, another level appeared in which the communicative and communicative function appeared, which is the deliberative level, that is, what the language circulation performs between the two parties to the discourse (the speaker and the speaker) in a social context. With this development, some researchers in the field of language went to re-study the rules of their languages. The Institute of the Russian Language of the Soviet Academy of Sciences issued in 1970 a new book for the grammar of the contemporary Russian language based on the functional structural theory, and studied many world languages from the sites of that theory, such as English, Czech and Japanese. ... and international conferences were held to discuss issues related to the functional division of the sentence. "(14) Thus, linguistic studies were launched through the universality of contemporary intellectual projects in the field of language. It thus differs from the old studies in terms of subject and purpose, in terms of "the subject of the study did not go beyond the limits of the old linguistic thought and the limits of this one language (Hindi, Arabic or French for example), while the subject of linguistics is the languages of different types, or rather the linguistic queen that Human beings are distinguished by them, so the main goal of linguistic studies in ancient times was to teach language and preserve it from being tainted by the tune of its people or those who came to it. In return for this, linguistics seeks, through the study of various types of languages, to establish (towards a holistic) that undertakes monitoring the natural characteristics of the tongue in general. 15), and on this basis, the career direction in linguistic studies has come to see that language is a man's means of communication and reporting and is linked to his social, cultural and civilizational principles, because "the functionally determinant of language is that it is a person's tool to accomplish the reporting process in the core of society, which enables the transformation of collective coexistence into a human institution. It has all the cultural and civilizational elements. "(16) One of the most important principles of functionalism in linguistic studies is that" natural languages determine their characteristics (at least partly). L) The conditions of its use within the framework of its basic function and the communication function. "(17) Among the most important functional theories that take into account the deliberative dimension in describing language is 
what was called (generative connotation) and the proposed functional theory within the framework of the American Harvard School, as well as European functional schools that The most important of them are (Systematic School) and (Prague School) and finally the functional grammar of (Simon Dick) (18) and the theory of functional grammar is one of the most important functional linguistic theories that has had a great impact in the field of modern linguistic studies. Most researchers in studies have accepted the ideas of this theory. Linguistics and they responded to everything new brought about by this theory, and there are those who called for a reconsideration of the principles and foundations of their theories, and some of them called for their abandonment and conversion to functional currents despite their previous studies as proponents of the transformative generative theory (19) and perhaps one of the most important reasons for that It is due to "it was interested in covering basic aspects of the linguistic phenomenon and filling gaps created by nondeliberative theories in vital axes such as (speech, context, circumstances of the discourse ...) and including all of this within the description and interpretation of linguistic phenomena." (20), the theory of functional grammar proposed by the linguist (Simon Dick) in 1970 is considered the most important functional linguistic theories as it constitutes a project of deliberative functional linguistics that goes towards globalism and geographical sweeping. It is a comprehensive pragmatic theory based on the principle of linguistic communication that forms Its subject (21) is the functionalist pragmatism theory that is more responsive to the requirements of modeling on the one hand and the conditions of theorizing on the other hand. Functionalism and philosophical theories: such as the theory of speech theory acts (22).

Thus, the theory of functional grammar is considered a project adopted by human minds, as it is an experiment that possesses a diffusive force among the scientific minds, even if it differs from it in the references where "the theory of functional grammar moved from its hometown Amsterdam to other countries and groups of functional research were formed in Antwerp (Belgium), Madrid and Rabat. And London and Denmark, and in parallel with that, functional researchers were invited to participate in international, European and American forums on the side of researchers from other generative transformative, relational, computational and other disciplines to compare different approaches to central linguistic phenomena, in an attempt to achieve standards of eloquence and the validity of structures, which is called by some linguists. The most important of which is matching the requirements of the occasion and the necessity of the case (23), or what is achieved in which its grammatical correctness is achieved through the so-called background of the function of communication and communication (24). Spreading along with more knowledge of it through international seminars that are held periodically, starting in Amsterdam in 1984, Antwerp in 1986, and Amsterdam in 1988, Denmark in 1990, Antwerp in 1992, New York in 1994, Cordoba in 1996, Amsterdam in 1998, Mohammedia in 1999, Madrid in 2000, Beni Mellal in 2001, Amsterdam in 2002, Agadir in 2003, Gijon in 2004, and San Paolo in Brazil in 2006. (25) We will talk about this theory in some detail. In later paragraphs.

2) The evolution of functional grammar theory after the transformative generative theory:

Since the theory of functional grammar has kept pace with the stages of development of the models of the transformative generative theory, we can summarize the most important points of difference between the two theories as follows:

A- Language selection:

The transformative generative theory believes that language is a group of linguistic sentences and that its function is limited to expressing thought, while the theory of functional grammar believes that language takes a more comprehensive role by describing it.

"A tool for social interaction, and hence its social function is to communicate in its broadest sense" (22).

B_ Dual Capacity _ Communicative:

"The ability in transformative generative grammar is the speaker's skill that enables him to produce and interpret sentences and judge their grammar" (26), and in the theory of functional grammar, the ability is not defined except in a specific communicative framework, as it represents the speaker's ability to interact socially through the pattern of linguistic use.

C - Linguistic acquisition:

The transformative generative grammar sees that the linguistic acquisition of the child is through the innate brain, while the theory of functional grammar believes that the linguistic acquisition of the child is through the discoveries that he makes.

From the above, we conclude from this difference that the theory of functional grammar differs from the transformative generative grammar in many linguistic issues, based on the principle of communication, 
which gave this theory a distinctive place among modern linguistic theories, which made linguists in general work in the fields of this theory, including Dr. Ahmed Al-Mutawakel Who transferred (Dick) grammatical theory to the Arabic language, and this is what we will address in later paragraphs.

2_ stages of development of the theory of functional grammar:

The functional grammar theory has passed through two basic stages, which can be summarized as follows:

The first stage is the sentence model stage (1978):

Simon Dick's book Functional grammar appeared at this stage.

It was followed by other research and literature all dealing with a topic towards sentence.

The second stage is the text model stage (1989):

It was at this stage that Simon Dick's book (The Theory of Functional Grammar) appeared.

(The theory of functional grammar), and this stage was distinguished from the first stage by new ideas that moved from the sentence to the text, and the author carried out studies and research conducted with a number of researchers, including Dr. And expanding its concepts (27).

Among the most important amendments to the theory of functional grammar include the following (28):

The transition from a simple form (sentence form) to a multi-template model (text form) that aspires to describe the different faculties that constitute the communicative ability of the speaker.

Reducing the load structure and the functional structure to a single infrastructure.

- Formulating the infrastructure to multiple levels of representation on the basis of its inclusion.

3- The most important functional principles in functional grammar theory:

Based on the criterion (job), which is the most important feature of the theory of functional grammar, the theorists of this theory have defined basic principles called (functional principles), the most important of which are summarized as follows (29):

A- (The communication function) The basic function of natural languages is based on the communicative purposes that are found in phrases as means to achieve communication.

B- (Functional dependency of structure) and determines the function of natural languages through the structural characteristics of these languages that include (exchange, syntax, and intonation).

C- (Communicative Competence): It represents the subject of the linguistic lesson in the two deliberative positions, which is describing the communicative ability of the speaker / addressee through a combination of grammar and deliberation.

D - Achieving three types of competencies, including the following:

Pragmatic adequacy is the link between the linguistic properties of phrases and how they are used within a particular context and denominator.

Psychological adequacy, in which the grammar rules during the production and understanding of the discourse correspond to the existing processes in the mind of the speaker / addressee and interpret the appropriate interpretation.

Typological adequacy is its attempt to develop a model that is semi-inclusive to achieve the description of the largest possible number of natural languages.

4- The communicative function in functional grammar theory:

The theory of functional grammar starts from the standpoint of describing natural languages functionally, on the basis that the structural characteristics of languages are defined (at least in part) by the communicative goals these languages seek to achieve (30). Most linguists have argued that language is a human and social phenomenon whose structures differ from society. To another, and all societies share one function, which is the function of (communication) among other people, which is its basic function.

Accordingly, the theory of functional grammar begins in its linguistic analysis through (communication) as the first principle that tops its methodological principles, on the basis that "the basic function of natural languages is the function of communication" (31) where participants interact in the process of producing discourse by changing their deliberative information and "the information is changed." Deliberative either by looking at the existing relationship between the speaker and the addressee or by looking at the content of the speech itself. In this second case, the intention of the speech is to compel the addressee to perform an action (directive communication), whether the required action is an act (commanding communication) or a saying (interrogative continuation) as it is. Its purpose is to inform about something (informative communication) or to express a feeling (expressive communication) or to arouse a feeling (excitatory communication) "(32). 
With this understanding of the communicative function, linguistic interaction takes place in a reciprocal relationship between the speaker, the addressee, and the text, based on the dimensions of the communicative process.

5- The theory of functional grammar represented by the Arabic:

This linguistic theory was transferred to the Arabic language through the Moroccan linguist Dr. Ahmed AlMutawakel, who made many attempts in many of his linguistic writings in which he tried to describe and explain many issues of the Arabic language from the point of view of the theory of functional grammar, where (Al-Mutawakkil) indicates that this theory was entered

"The Arab world was the first to enter the University of Mohammed V in Rabat, where it was formed (the Research Group on Circulations and Functional Linguistics), and thanks to the efforts of Moroccan researchers belonging to this group, the career orientation was able to take its place in Moroccan linguistic research along with its other components. This was done in four main ways. It is teaching, academic research, publishing and holding international seminars inside Morocco itself. "(33) The goal of (Al-Mutawakkil) since 1972 to the present day includes establishing a functional approach for the Arabic language that includes all its levels, as he says:" We tried our best in this group of studies. That we share two goals: to enrich the linguistics of the Arabic language by providing functional descriptions of phenomena that we consider central to the semantics, structures, and deliberations of this language, and to graft functional grammar whenever the need arises with concepts that require adequate description of this or that phenomenon. "(34) This means that the goal of (Al-Mutawakil) is from Adopting the theory of functional grammar in the Arabic language consists in providing functional descriptions of linguistic phenomena and their interpretation from a functional perspective, that is, adding new knowledge and investigations of Arabic linguistics.

From the foregoing it becomes clear that (al-Mutawakkil) does not stand the stance of reducing or canceling the old linguistic master, and does not stand the position of the venerable fanatic to him, because he believes that this achievement has conditions that produced it and goals that contributed to directing it to be in the way it is, and that the evaluator or evaluator of this achievement must He takes into account this matter related to the conditions of linguistic production, where he says: "The evaluators of the old linguistic lesson in general (Arab or non-Arab) take two positions, among them those who believe that there is no difference between the old and the modern, and that the old calls the hadith if he does not prefer it, but refuses to subjugate it. Some of them evaluate the old on the basis of what is stipulated in the hadith and reject the old altogether, considering its scientific shortcomings. The correct position in our view is the following position: The old linguistic lesson has its features and characteristics that are the product of its historical context and its cognitive environment, so in order to avoid dropping and moderation together. We must judge in our evaluation of this product what we judge in evaluating modern linguistic theories, especially the standards of contemporary sciences and techniques, but this discrepancy has reached what it has reached, and does not raise in our regard, the existence of concepts and functional approaches in the old linguistic lesson, even if it is called by Terms of knowledge of that era "(35).

Those working in the functional Arabic language were able to achieve the following (36):

A - Achievement towards a career that is incremental to the Arabic language that develops with the development of the general theory.

B - Achieving participation in public theorising by proposing new models and modifying existing ones.

$\mathrm{C}$ - The openness of functional theory to the social and economic fields, in addition to the purely linguistic field of study.

\section{Conclusion}

As a result of what has been presented in this research, it becomes clear to us that structural linguistics is no longer the dominant studies in the field of linguistic studies. This is because contemporary linguistic studies provided functional linguistic models that resulted in linking the language to its users, and this linkage explains the characteristic that characterized the nature of the speech of the human being that is produced for a communicative purpose aimed at communicating with all human societies.

The theory of functional grammar is the most recent model of linguistic studies that tried to complement the deficiencies or angles in previous studies, and this theory still dominates a wide area of linguistic studies, and that researchers in it are still experimenting with natural languages based on the European project led by (Simon Dick) And many researchers, all the way to the Arab environment, represented by (Ahmed AlMutawakel's) attempts to apply this theory to the Arabic language. 
Margins

1- Studies on functional Arabic language, Al-Mutawakel: 26.

2- See: General Linguistics, Ferdinand de Saussure, translated by: Dr. Joel Youssef Aziz: 30.

3- See: Saussure and linguistics among the most important schools of linguistics, Muhammad al-Shaoush and others: 14.

4- See: the same source: 17.

5- Looking at: Studies in the Career of the Arabic Language, Al-Mutawakel: 26.

6- Functional orientation and its role in language analysis, Yahya Ahmed: Journal of Linguistic Thought, vol. 3, 1989,70

7 - See: functional linguistics and the Arabic language, Dr. Abd al-Qadir al-Fihri: 39.

8- Consider: structuralism in contemporary philosophical thought, Omar Muhaybel: 20.

9- Saussure and linguistics within the most important linguistic schools: 5.

10- See: functional linguistics (theoretical introduction) Al-Mutawakel: 30.

11- See: Structuralism in Linguistics, Muhammad Al-Hanash: 96

12- See: Modern Arab Linguistic Theory, Arab Writers Union: 61.

13- See: Investigations in Linguistics, Office of University Publications, Algeria: 13.

14- Language Questions, Linguistics Questions, Dr. Hafez Ismail Aliwi, and Dr. Walid Ahmed Al-Anati: 38.

15- Linguistics and its Epistemological Foundations, Dr. Abd al-Salam al-Masadi: 31.

16- The deliberative functions in the Arabic language, Al-Mutawakel 8.

17- Looking at: Studies in the Functioning of the Arabic Language: 26.

18- The summary on explaining the evidence of miracles in the science of meanings, Jaafar Dak, Chapter: 116.

19- See: A Brief History of Linguistics (in Morocco), Rubens, translation: Ahmed Awad: 328.

20- Career in the Arab linguistic heritage, Masoud Sahrawi, Journal of Linguistic Studies, published by the King Faisal Center for Research and Islamic Studies, Saudi Arabia, Volume Five, Issue 1, 2003, 3.

21 - See: Philology and Linguistics, Mahmoud Suleiman Yaqout, 225.

22- See: deliberative functions in the Arabic language: 9.

23- Consider: in Arabic grammar, criticism and direction, Dr. Mahdi Makhzoumi: 226.

24- The New Arab Functional Approach to Renew Arabic Grammar, the works of the symposium Facilitating Grammar: 282.

25- The career orientation in Arab thought (origins and extension) al-Mutawakkil: 60-61.

26- Functional Linguistics (theoretical introduction) Dr. Ahmad Al-Mutawakel: 104.

27- Towards a functional theory of Arabic compassion, a PhD thesis, Yahya Baitish: 420.

28- See: Arabic grammar between modernization and facilitation, Yahya Baitish: 122.

29- New perspectives in the theory of functional grammar, Dr. Ahmad Al-Mutawakel: 5.

30- See: deliberative functions in the Arabic language, Dr. Ahmad Al-Mutawakel: 11, lessons in applied linguistics, Saleh Belaid: 10, and function and structure, Dr. Ahmad Al-Mutawakel: 5

31- See: deliberative functions in the Arabic language: 10, philology and linguistics: 225.

32- Studies in the direction of functional Arabic: 9.

33- Functional linguistics (theoretical introduction) 51.

34- The career orientation in the Arabic linguistic thought (origins and extension): 61.

35- Linguistics in Contemporary Arab Culture (An Analytical Critical Study of Receptivity Issues and Its Problems) Hafez Ismail Aliwi: 348.

36- The career orientation in Arabic linguistic thought (origins and extension): 53-161.

\section{Sources and references}

- Functional orientation and its role in language analysis, Yahya Ahmed: Al-Fikr Al-linguistics Journal, Volume 3, 1989 AD.

- Language questions, questions of linguistics, d. Hafez Ismail Aliwi and Dr. Ahmed Al-Anani, Dar Al-Aman, Rabat, 2nd Edition, 2009 AD.

- New horizons in the theory of functional grammar, Dr. Ahmed Al-Mutawakel, Faculty of Arts, Rabat, Morocco, 1st Edition, 1993 AD.

- Structuralism in Contemporary Philosophical Thought, University Publications Bureau, Algeria, 1991 AD.

- Structuralism in Linguistics, Muhammad Al-Hanash, Dar Al-Rashad Modern, Casablanca, Morocco, 1980 AD.

- Studies in Arabic Language Career, Dr. Ahmed Al-Mutawakel, House of Culture, Casablanca, 2nd Edition, 1988. 
- Lessons in Applied Linguistics, Salih Belaid, Dar Hawma for Printing and Publishing, Algeria, 2000 AD.

- Saussure and Sunni among the most important schools of linguistics, Muhammad Chaouch and others, the National Institute for Educational Sciences, Tunis, 2nd Edition, 1990 AD.

- General Linguistics, Ferdinand de Saussure, translated by: Dr. Joel Youssef Aziz, revised by: Dr. Malik Youssef, Dar Afaq Arabia, Baghdad (d.

- Philology and Linguistics, Muhammad Suleiman Yaqout, University Knowledge House, Alexandria, Egypt, (d.

- In Arabic grammar (criticism and direction), Dr. Mahdi Makhzoumi, Dar Al-Raed Al-Arabi, Beirut, 2nd Edition, 1986 AD.

- Functional linguistics (theoretical introduction) Dr. Ahmed Al-Mutawakel, Al-Kitab Al-Jadeed United House, Beirut, 2nd Edition, 2010 AD.

- Functional linguistics and the Arabic language (synthetic and semantic models) d. Abdelkader Fassi Al-Fihri, Dar Toubkal, Casablanca, Morocco, 1st Edition, 1985 AD.

- Linguistics in Contemporary Arab Culture (a critical analytical study on the issues of receptivity and its problems) Hafez Ismail Aliwi, The New United Book House, Beirut, 1st Edition, 2009 AD.

- Linguistics and its cognitive foundations, d. Abdel Salam Al-Masdi, Tunisian Publishing House, Tunis, 1996.

- Investigations in Linguistics, University Press Office, Algeria, 1999 AD.

- Career orientation in the Arab linguistic heritage, Masoud Sahrawi, Journal of Linguistic Studies, published by the King Faisal Center for Research and Islamic Studies, Saudi Arabia, Volume Five, Issue 1, 2003 AD.

- The career orientation in Arab thought (Origins and Extension) Dr. Ahmed Al-Mutawakel, House of Culture, Rabat, Kingdom of Morocco, 1st Edition, 2006 AD.

- The New Arab Functional Approach for the Renewal of Arabic Grammar, Symposium Facilitating Grammar, 2001.

- Brief History of Linguistics (in Morocco) Translated by: Ahmed Awad, The World of Knowledge Series, Kuwait (dt).

- The Summary on Explaining Evidence for Miracles in the Science of Meanings, Jaafar Dak Al-Bab, Galilee Press, Damascus, 1980 AD.

- Arabic Grammar between Modernization and Facilitation, Yahya Baitish, Works of Symposium on Facilitating Arabic Grammar, Publications of the Supreme Council of the Arabic Language, National Library of Hamma, 2001 AD.

- Towards a Functional Theory of Arabic Grammar, Yahya Baitash, PhD thesis, University of Manchoury Constantine, Faculty of Letters and Languages, Algeria, 2006 AD.

- Modern Arabic Linguistic Theory, Arab Writers Union, Damascus, Syria, 1st Edition, 1996 AD.

- deliberative positions in the Arabic language, Dr. Ahmed Al-Mutawakel, House of Culture, Casablanca, Morocco, 1st Edition, 1985 AD.

- deliberative positions in the Arabic language, Dr. Ahmed Al-Mutawakel, House of Culture, Casablanca, Morocco, 1st Edition, 1985 AD.

Function and structure, d. Ahmed Al-Mutawakel, Okaz Publications, Rabat, 1993. 